\title{
Reflexões sobre o papel do antropólogo nas ações de salvaguarda do patrimônio imaterial no estado do Rio de Janeiro1
}

\author{
Vítor Gonçalves Pimenta \\ Doutorando em Antropologia pelo PPGAS \\ Universidade Federal Fluminense
}

Resumo: Este trabalho tem como objetivo refletir sobre o imbricamento do antropólogo e as políticas públicas, no que toca à implementação de ações de salvaguarda do patrimônio imaterial no estado do Rio de Janeiro, focando no Comitê Gestor do Ofício das Baianas de Acarajé. Busca-se aqui refletir sobre os usos sociais do patrimônio neste ambiente interinstitucional, e investigar a relação dialógica do ofício do antropólogo no curso dos encontros institucionais e profissionais no âmbito da esfera pública.

Palavras-chave: patrimônio; antropólogo; salvaguarda; política; memória afro-brasileira.

\footnotetext{
${ }^{1}$ Este artigo é fruto do aprofundamento dos trabalhos apresentados na $30^{a}$ Reunião Brasileira de Antropologia, na X Jornada de Alunos do Programa de Pós-Graduação em Antropologia da Universidade Federal Fluminense e na XVII Jornada do Programa de Pós-Graduação em Sociologia e Antropologia da Universidade Federal do Rio de Janeiro, realizadas no ano de 2016. Agradeço o apoio fundamental do meu orientador Julio Cesar de Tavares e a colaboração inestimável de Lívia Buxbaum e Daisy Sena.
} 


\title{
Reflexion upon the anthropologist's role in actions for safeguarding intangible heritage in Rio de Janeiro State
}

\begin{abstract}
This work aims to reflect on the imbrication of the anthropologist and public policies, regarding the implementation of actions to safeguard intangible heritage in the state of Rio de Janeiro, focusing on the Management Committee of the Office of the Baianas of Acarajé. This research aims to reflect on the social uses of heritage in this interinstitutional environment and to investigate the dialogical relationship of the anthropologist's office in the course of institutional and professional meetings within the public sphere.
\end{abstract}

Keywords: heritage; anthropologist; safeguarding; policy; Afro-Brazilian memory.

\section{Reflexiones sobre el papel del antropólogo en las acciones de salvaguardia del patrimonio inmaterial en el estado de Rio de Janeiro}

Resumen: Este trabajo tiene como objetivo reflexionar sobre el imbricamiento del antropólogo y las políticas públicas, en lo que se refiere a la implementación de acciones de salvaguardia del patrimonio inmaterial en el estado de Río de Janeiro, enfocándose en el Comité Gestor del Oficio de las Baianas de Acarajé. Se busca aquí reflexionar sobre los usos sociales del patrimonio en este ambiente interinstitucional, e investigar la relación dialógica del oficio del antropólogo en el curso de los encuentros institucionales y profesionales en el ámbito de la esfera pública.

Palabras clave: patrimonio; antropólogo; salvaguardia; política; memoria afro-brasileña. 


\title{
Introdução
}

Pareceu-me pertinente abordar algumas questões referentes às minhas primeiras experiências como participante do Comitê Gestor do Ofício das Baianas de Acarajé, visto que cada vez mais o ofício do antropólogo é chamado a integrar os ambientes institucionais. Assim, neste trabalho, busco questionar a minha atuação como antropólogo na esfera pública, uma vez que os meus conhecimentos antropológicos são chamados a entrar em um debate público. Diante deste desafio, sou impelido a tratar de questões antropológicas de ordem teórica e ética. Como bem afirmou Alcida Ramos, "no Brasil, como em outros países da América Latina, fazer antropologia é um ato político" (RAMOS, 1990, p. 1). Em outras palavras, começo a refletir sobre o que a Antropologia tem a dizer sobre o trabalho do antropólogo no desenvolvimento de políticas públicas. A questão é pensar sobre a implementação de ações de salvaguarda do patrimônio imaterial no estado do Rio de Janeiro, no âmbito do acordo de cooperação técnica entre o Instituto do Patrimônio Histórico e Artístico Nacional (Iphan) e a Universidade Federal Fluminense (UFF). Este instrumento interinstitucional visa efetivar ações conjuntas entre Iphan/RJ e UFF, por meio do Laboratório de Etnografia e Estudos em Comunicação, Cultura e Cognição (LEECCC), do qual faço parte, com o objetivo de viabilizar a otimização da pesquisa, identificação, mapeamento, preservação, salvaguarda, valorização e difusão da memória social e do patrimônio cultural através da realização de estudos técnicos, pesquisas, palestras, cursos, seminários, simpósios, congressos, encontros nacionais e internacionais, debates e oficinas, na área do Patrimônio Imaterial do Rio de Janeiro. No âmbito das políticas públicas na esfera do patrimônio, de acordo com o Iphan:

\begin{abstract}
os planos de salvaguarda organizam os investimentos necessários para promover a continuidade, social e ambientalmente sustentada, dos bens culturais registrados. A participação ativa da base social que detém e dá sustentação a esses bens é fundamental, assim como da sociedade em geral e de parceiros governamentais que possam contribuir no processo de salvaguarda. Por isso, em cada plano deve ser constituído um Comitê Gestor, composto pelos parceiros mais diretamente envolvidos na sua execução e, ainda, uma Comissão Consultiva ou Conselho, que reúne, mais amplamente, os indivíduos e as instituições que podem, com sua expertise ou por meio de sua estrutura de apoio, colaborar para o sucesso dos planos de salvaguarda (IPHAN, 2014, p. 47).
\end{abstract}

Com base nessas estruturas organizacionais, analiso minha participação como antropólogo no Comitê Gestor do Ofício das Baianas de Acarajé, o qual foi instituído no dia 23 de outubro de 2015, e passarei a denominar aqui apenas por Comitê. Segundo o Iphan, o papel do Comitê Gestor é "elaborar, executar e avaliar ações, além de fazer o acompanhamento dos seus desdobramentos, aos detentores é atribuído um papel primordial, uma vez que eles detêm o conhecimento e a responsabilidade de execução do bem em questão" (IPHAN, 2014, p. 69).

Nesse contexto de cooperação, o grupo que integra o Comitê2 compôs-se pelos representantes do Instituto do Patrimônio Histórico e Artístico Nacional

${ }^{2}$ Decidi, neste primeiro momento, não colocar nenhum nome dos integrantes do Comitê, dado que não tive a 
(Iphan/RJ), Centro Cultural Cartola, Associação das Baianas de Acarajé, Mingau, Receptivo e Similares do Rio de janeiro (ABAM/RJ), Instituto Estadual do Patrimônio Cultural (INEPAC), Universidade Federal Fluminense (UFF), Conselho Municipal de Defesa dos Direitos do Negro (COMDEDINE), Secretaria Municipal de Cultura (SMC), Organização Remanescentes de Tia Ciata, além de quatro baianas. Outras instituições e detentoras chegaram posteriormente. Segundo o primeiro documento elaborado pelo grupo, os Comitês gestores são dispositivos de organização previstos nos termos de referências, cujo trabalho a ser desenvolvido envolve a participação interinstitucional.

A partir dessa primeira reunião, na qual não estava presente, iniciei uma reflexão sobre o meu papel no Comitê, buscando informações com os integrantes sobre o que tinha acontecido nesse dia de formalização institucional do Comitê. Este momento analítico apenas ocorreu quando soube que iria participar da próxima reunião através do LEECCC, marcada para o dia 17 de dezembro de 2015. Logo em seguida, comecei a pensar que a minha maior contribuição ao coletivo seria como pesquisador no campo da Antropologia. Entretanto, como antropólogo, tenho a tendência de participar efetivamente da instituição que integro e, concomitante, refletir sobre o papel institucional da mesma. Imagino que essa seja uma marca do ofício ao atuar em um ambiente institucional. Esse tipo de envolvimento ocorreu quando participei do projeto "Uma proposta de Habitat Saudável em comunidade vizinha ao Campus Fiocruz da Mata Atlântica: Geração de metodologias e intervenção social para a melhoria do ambiente construído"3, cujo referencial conceitual encontrava-se pautado nos Determinantes Sociais da Saúde (DSS) de janeiro de 2009 a dezembro de 2010. Nesta espécie de experimentação in vivo (LAPLANTINE, 2004), senti e pensei a minha inserção e relação com a instituição na forma de um grande "laboratório".

\begin{abstract}
O objeto de pesquisa não era somente aqueles elaborados e presentes nos projetos da instituição, mas, acima de tudo, o meu grande objeto era desenvolver uma reflexão sobre a atuação da Fiocruz na localidade. Em outras palavras, o meu intuito era desvelar por quais caminhos as relações sociais se processam no encontro entre o saber formal institucional e o saber oral local, uma vez que a instituição adota uma linha de participação social no desenvolvimento dos seus projetos (PIMENTA, 2015, p. 20).
\end{abstract}

Assim, como antropólogo, tenho a inclinação de aproximar, pelo menos mentalmente, uma atividade de trabalho institucional aos moldes de um trabalho de campo. Todavia, "como disse Sartre: O aluno atento que deseja ser atento, olhos fixos no professor, ouvidos bem abertos, consome-se tanto em representar o papel de atento que termina por não ouvir mais nada" (SARTRE4, 1956 apud GOFFMAN, 2008, p. 39). Dessa maneira, considero-me, ou colocome, ou como agente, sujeito do Comitê, ou observador do Comitê. Digo isso especificamente em relação ao momento em que nos reunimos para discutir as questões pertinentes às políticas de salvaguarda do ofício das baianas de acarajé.

oportunidade de me reunir com todo o grupo para discutir tal questão.

${ }^{3}$ Projeto contemplado com os recursos públicos do Edital Cidades Saudáveis 1/2007, "Cidades Saudáveis: Saúde, Ambiente e Desenvolvimento", que visava à realização de pesquisas que pudessem resultar em tecnologias cabíveis de serem utilizadas no SUS e/ou na gestão ambiental.

4 SARTRE, Jean-Paul. Being and Nothingness. Trad. por Hazel E. Barness. Nova Iorque: Philosophical Library, 1956. 
Nessas interações com os membros do Comitê, apresentou-se o dilema expressão versus ação, isto é, ou você desempenha bem uma tarefa ou a representa. $\mathrm{O}$ desafio que se apresenta nesses contextos interinstitucionais a nós antropólogos é de mantermos a nossa coerência ética e antropológica com todos os participantes e, concomitantemente, deixarmos claro aos mesmos, que a nossa missão é questionar o que achamos que estamos fazendo nesse ambiente institucional. Depois dessa reminiscência, ainda caminhando com muitas dúvidas, busquei participar do Comitê como um membro efetivo, refletindo criticamente sobre as trocas existentes no encontro com os demais membros, mesmo que ainda me comportando timidamente nesses encontros iniciais.

\section{A questão do patrimônio}

A troca que mais me afetou até este exato momento no qual escrevo foi a primeira que tive quando entrei na sala de reunião do Iphan, localizado no Centro do Rio de Janeiro. Antes de chegar ao endereço, na Avenida Rio Branco, $\mathrm{n}^{0} 46$, imaginei como seria a arquitetura da casa do Iphan, que abrigaria as nossas reuniões, pensando no significado que essas linhas históricas edificadas outrora teriam para os membros do Comitê. Logo de cara, me deparei com um portal de madeira todo trabalhado por hábeis mãos. Ao transpor esse portal, tentei me transportar para a época da construção do prédio. A minha caminhada pelo interior do prédio até a sala de reunião no $3^{\circ}$ andar foi marcada por um olhar curioso e reflexivo sobre cada detalhe arquitetônico que me saltava aos olhos, principalmente os arabescos expostos nos tetos e as portas e janelas de madeira. Eu olhava e me perguntava o seguinte: quem foi o trabalhador, o artesão que construiu esta peça? Pois, mesmo sem ter a confirmação oficial, sabia que tinha adentrado em um prédio tombado, e isto, de alguma forma, pesava sobre meus olhos. Era como se a ideia de tombamento me trouxesse, naquele instante, um ar de notabilidade àquele prédio. Entretanto, simultaneamente, exigia que o prédio - tombado pelo Iphan em 1978 por sua importância histórica e artística - se transmutasse em atores concretos.

Queria entender a partir daqueles passos até o meu destino, ou seja, a sala de reunião, o ofício dos trabalhadores que construíram aquele edifício. Ao pesquisar, descobri que esse prédio, inicialmente, abrigou a Companhia Docas de Santos, foi projetado pelo engenheiro paulista Ramos de Azevedo e erguido entre os anos 1905 e 1908, na antiga Avenida Central, em comemoração ao centenário da abertura dos portos do Brasil (JORNAL DO BRASIL, 2012). Neste ínterim, entre o meu primeiro olhar de espanto, provocado por aquelas curvas históricas e a minha chegada à sala de reunião, parecia que, intuitivamente, ao chocar-me com o prédio, estava questionando as definições de patrimônio material e imaterial, pois enxergava em cada peça de madeira a imaterialidade do ofício dos construtores impregnada naquelas paredes. Por outra forma, no prédio tombado, o ofício de todos os construtores, do arquiteto aos operários, materializa-se nas formas do edifício. A materialidade expressava uma imaterialidade. O prédio, corpos e ofícios se formavam um todo nos meus pensamentos, questionando a indissociabilidade do patrimônio. 
Abro um parêntese para trazer outro exemplo sobre esta relação entre bem material e bem imaterial, que perpassa outros espaços e instituições, lembrando de um episódio que aconteceu em sala de aula, quando, em 2015, lecionei a disciplina Sociologia no Colégio Anglo-Americano na Barra da Tijuca. Em uma das avaliações do $1^{\circ}$ ano do Ensino Médio, coloquei uma questão do Enem PPL 2014 sobre a temática do patrimônio, que era baseada no texto "A diferença entre o acarajé e o sanduíche de Bauru", de Kaz (2006), onde o autor apresenta uma reflexão sobre o ofício das baianas de acarajé, sublinhando que este ofício não se configura sendo a receita do acarajé. O ofício versa sobre o preparo do acarajé, quando o fazer é cercado por uma série de códigos imperceptíveis para quem observa de fora. Nesse sentido, a cor da roupa, a amarra dos panos e os adereços mudam de acordo com o santo e com a hierarquia ocupada pela baiana no candomblé. Ao registrar esse bem imaterial como patrimônio cultural, o Iphan busca descortinar as dimensões ligadas ao preparo do acarajé. Com essa mesma abordagem, desde 2002, o Iphan tem registrado certos bens imateriais como patrimônio cultural do país. A questão, com cinco opções de resposta, solicitava ao candidato destacar a melhor alternativa, de acordo com o texto, na qual o Iphan evidencia a necessidade de proteger certas manifestações culturais para que elas continuem a existir. A resposta correta, de acordo com o gabarito, era a afirmativa que destacava a relação com o sagrado no ato de preparar o alimento, sobressaindo-se o uso de símbolos e insígnias pelas cozinheiras. Entretanto, quando discuti a questão com os estudantes, eles me indagaram sobre a imaterialidade do ofício, pois a baiana produz um bem material, o acarajé, o que gerou dúvidas sobre se o ofício era imaterial ou material. Essa discussão me fez refletir sobre o ofício que produz uma materialidade, neste caso, o bolinho de acarajé - um bem material comestível, que tem uma vida efêmera.

Como se observa, a partir dos exemplos do prédio do Iphan e do bolinho de acarajé, nessa relação entre o ofício e o bem, existe uma materialidade no ofício e uma imaterialidade no bem. Ambos acabam se misturando, fazendo parte um do outro, sendo difícil pensá-los de maneira dissociável. Esta é a primeira questão que gostaria de colocar aqui: um convite para refletirmos sobre os imbricamentos entre o patrimônio material e imaterial, para que não tenhamos uma visão estática e "pura" desses conceitos, levando em consideração tanto as concepções do observador quanto as concepções nativas. Conforme nos aponta José Reginaldo Gonçalves, "recentemente construiu-se uma nova qualificação: o 'patrimônio imaterial' ou 'intangível'. Opondo-se ao chamado 'patrimônio de pedra e cal', aquela concepção visa aspectos da vida social e cultural dificilmente abrangidos pelas concepções mais tradicionais" (GONÇALVES, 2007, p. 111). O foco encontra-se nos aspectos ideais e valorativos das formas de vida e menos nas dimensões materiais. Assim, a política do patrimônio imaterial "não se propõe 'tombar' os bens listados nesse patrimônio. A proposta é no sentido de se 'registrar' essas práticas e representações e de se fazer um acompanhamento para verificar sua permanência e transformações"5. Para o autor, com tal iniciativa, abre-se a possibilidade de se aprofundar as reflexões sobre os diversos significados que essa categoria pode assumir. 
Atento a esse caráter cambiante e dinâmico do patrimônio, devemos dialogar e refletir sobre os princípios norteadores que construíram o instituto do registro como instrumento de reconhecimento e valorização do patrimônio imaterial.

\begin{abstract}
O primeiro princípio vincula-se à própria natureza desse tipo de bem. Oriundos de processos culturais de construção de sociabilidades, de formas de sobrevivência, de apropriação de recursos naturais e de relacionamento com o meio ambiente, essas manifestações possuem uma dinâmica específica de transmissão, atualização e transformação que não pode ser submetida às formas usuais de proteção do patrimônio cultural. O patrimônio imaterial não requer "proteção" e "conservação" no mesmo sentido das noções fundadoras da prática de preservação de bens culturais móveis e imóveis - mas identificação, reconhecimento, registro etnográfico, acompanhamento periódico, divulgação e apoio. Enfim, mais documentação e acompanhamento e menos intervenção. O segundo princípio, decorrente do primeiro, é a não aplicabilidade ao patrimônio imaterial do conceito de autenticidade, tal como comumente utilizado no campo da preservação. Neste caso, a noção de autenticidade deve ser substituída pela ideia de continuidade histórica, identificada por meio de estudos históricos e etnográficos que apontem as características essenciais da manifestação, sua manutenção através do tempo e a tradição à qual se vinculam. Essa noção de continuidade histórica e o reconhecimento da dinâmica própria de transformação do bem imaterial conduziram à proposição de uma ação fundamental: o acompanhamento periódico da manifestação para avaliação de sua permanência e registro das transformações e interferências em sua trajetória (BRASIL, 2006, p. 19).
\end{abstract}

Se, por um lado, é louvável a institucionalização da categoria "patrimônio imaterial" pelos órgãos de estado, como Iphan e INEPAC, por exemplo, no sentido de ampliar a noção de patrimônio mais conservadora, ligada ao aspecto material, ao mesmo tempo cria-se uma dicotomização institucional que separa as políticas do patrimônio em material e imaterial, construindo-se departamentos distintos do patrimônio. Assim, os dois patrimônios são operacionalizados de modos separados e por profissionais específicos devido às suas características. Não por acaso, observa-se muitos antropólogos ocupando cargos no departamento de patrimônio imaterial, diferentemente do setor material, onde a responsabilidade fica a cargo, principalmente, de arquitetos e historiadores. Por outro lado, com essa política desassociada dos patrimônios, surge o desafio de realizar políticas de salvaguarda do patrimônio imaterial que contemplem variadas concepções de patrimônio entre instituições públicas e detentores, uma vez que "a categoria 'patrimônio', em suas variadas representações, parece confundir-se com as diversas formas de vida e de autoconsciência cultural” (GONÇALVES, 2007, p. 115).

Dessa maneira, o desafio que se coloca ao Comitê na implementação de ações de salvaguarda do patrimônio imaterial é o de contemplar concepções de patrimônio diferentes entre, por exemplo, instituições responsáveis pelo patrimônio imaterial, como as citadas acima e as detentoras da manifestação cultural, caso das baianas de acarajé. A concepção formal pensa a dimensão material e imaterial de maneira separada, sendo caracterizada pela forma como as instituições são organizadas. A política salvaguarda apenas o ofício das baianas de acarajé, destacando os elementos simbólicos em detrimento dos elementos materiais.

Os aspectos referentes ao Ofício das Baianas de Acarajé e sua ritualização compreendem: o modo de fazer as comidas de baianas, com distinções referentes à oferta religiosa ou à venda informal em logradouros soteropolitanos; os elementos associados à venda como a indumentária própria da baiana, a preparação do tabuleiro e dos locais onde se instalam; os significados atribuídos pelas baianas ao seu 
A concepção de patrimônio elaborada pelas baianas "é baseada em categorias totais, envolvendo técnicas corporais, categorias sensíveis, jurídicas, estéticas e, principalmente, pautada em relações específicas com as religiões afro-brasileiras" (BITAR, 2011, p. 248). As detentoras não desassociam os patrimônios. O bolinho, a indumentária, o tabuleiro, o ponto de trabalho não são desagregados ao ofício de ser baiana. Esses bens são simultaneamente de natureza política, estética, religiosa, mágica, econômica, moral, jurídica, psicológica, fisiológica. Marcel Mauss chamou essa configuração de "fatos sociais totais" (MAUSS, 1974). "São, de certo modo, extensões morais de seus proprietários e estes, por sua vez, são partes inseparáveis de totalidades sociais e cósmicas que transcendem sua condição de indivíduos" (GONÇALVES, 2007, p. 110). Assim, ser baiana de acarajé ultrapassa os limites do oficio e do bolinho, configurando-se em uma experiência de estar no mundo.

\section{O antropólogo na prática}

Vejamos adiante como essas concepções do patrimônio dialogam no interior do Comitê. Agora, volto à caminhada até a sala de reunião, pois foi justamente esta a questão que me acometeu naqueles instantes antes de alcançar o espaço no $3^{\circ}$ andar, ou seja, percebi que a minha contribuição no espaço do Comitê devia ser pautada por uma reflexão e um questionamento permanentes da categoria patrimônio e as demais existentes nesse universo, levando em consideração que o patrimônio imaterial é marcado pelo seu caráter dinâmico, mutável. Nesse movimento ininterrupto, precisamos buscar novos caminhos na compreensão do trabalho antropológico, permitindo-nos avançar de maneira criativa e dialógica na relação de alteridade com o outro, fundamento central na construção da antropologia.

Ao adentrar a sala, encontrei uma baiana sentada em uma das cadeiras de madeira, dispostas à volta de uma grande mesa oval de jacarandá. Apresenteime como pesquisador da UFF e a senhora apresentou-se como baiana de acarajé. Em ato contínuo, ela sacou da bolsa o livro Baianas de acarajé: comida e patrimônio no Rio de Janeiro, de Nina Pinheiro Bitar. Mostrou-me sua foto estampada na página do livro e disse-me, orgulhosa, que foi protagonista dessa obra. Já com o livro em mãos, comecei a folheá-lo e anotar algumas referências que considerei importante naquele momento. Devolvi-o e a parabenizei por sua participação. Nesse instante, vejo-me refletindo sobre a especificidade e relatividade do ofício do antropólogo, fruto da nossa própria experiência, assumindo integralmente aquilo que DaMatta denominou Anthropological Blues. "Trata-se de incorporar no campo mesmo das rotinas oficiais, já legitimadas como parte do treinamento do antropólogo, aqueles aspectos extraordinários, sempre prontos a emergir em todo o relacionamento humano" (DAMATTA, 1978, p. 28-29). O extraordinário naquele instante era o diálogo via livro, marcado pela materialização da imaterialidade do ser baiana de acarajé.

Esse encontro revelou-me, depois de um exercício de exotização do familiar (DAMATTA, 1978) e de transformação do familiar em conhecido 
(VELHO, 1978), os meandros da relação entre antropólogo e interlocutor, uma prática comprometida com as esferas ética e moral, que respeita as negociações entre os sujeitos. "A prática designa as regras de conduta individual e coletiva, o sistema de direitos e deveres, em uma palavra as relações morais dos homens entre si” (LÉVY-BRUHL6, 1910, p. 9 apud OLIVEIRA, 2004, p. 22). Naquela apresentação, vislumbrei de alguma forma como os interlocutores se apropriam dos trabalhos acadêmicos produzidos pelos antropólogos, reutilizando-os em suas práticas sociais. Percebi que na, relação com o outro, ter um "documento", nesse caso um livro, torna o detentor diferenciado, pois há algo material que comprova aquilo que o detentor afirma ser. Assim, o livro é uma testemunha que evidencia não só o ofício da baiana de acarajé, mas o ser baiana de acarajé.

Aquele ato, marcado pelo encontro entre antropólogo e baiana, tornou-se cada vez mais inteligível com o desenrolar das reuniões do Comitê. Participei de três reuniões do Comitê até janeiro de 2016, período do nosso último encontro. As questões que discutimos e que me chamaram a atenção em um primeiro momento, fora a questão política do país - simbolizada pela tentativa de "impeachment"7 e os seus desdobramentos na atuação do Iphan -, passaram sobre o questionamento do que é ser baiana, a exigência dos documentos necessários para obter-se a licença do ponto de trabalho e a problemática do reconhecimento das baianas de acarajé, para além das questões de mercado, considerando que o acarajé insere-se em uma gastronomia afro- brasileira. Sobre o primeiro ponto, o Comitê seria o responsável em denominar quem é baiana ou não. A respeito da licença, a Secretaria Municipal de Ordem Pública (SEOP) e o Iphan estão se articulando para equacionar o problema. A questão do reconhecimento foi apresentada de maneira mais direta no seminário em 25 de janeiro de 2016, quando as baianas, organizadas em uma mesa, afirmaram que sofrem preconceito por serem baianas e reafirmaram a luta contra a intolerância religiosa, principalmente por parte dos evangélicos.

Essas discussões travadas ao longo da breve vida do Comitê ajudaram-me a descortinar o ato de apresentação da baiana oralmente, e, mais ainda, documentalmente. Ao se apresentar pessoalmente e por meio de um livro - um objeto escrito por um sujeito -, a baiana utilizou dois saberes, o oral e o escrito. O oral, de domínio do grupo de baianas. A escrita, de domínio dos antropólogos e dos pesquisadores em geral. Isso não quer dizer que esses saberes sejam exclusivos de um grupo ou de outro, apenas que um grupo pode ser definido pelo uso profissional desses saberes. Para além desta dicotomia, as baianas dominam uma gama de linguagens não verbais e práticas que as definem como baianas de acarajé. Assim também, o trabalho do antropólogo, exige mais do que o escrever, o domínio de outras formas de "faculdades de entendimento", como o olhar e o ouvir, para ficarmos com os exemplos tratados por Oliveira (2000).

O caráter documental da apresentação da baiana nos sugere, por um lado, que se transformar em protagonista de um trabalho acadêmico traz certo tipo de reconhecimento ao ser baiana. Por outro lado, devemos indagar como o nosso reconhecimento como "experts" em patrimônio impacta e é usado pelos detentores em suas práticas sociais. Não podemos nos esquecer qual é o

\footnotetext{
${ }^{6}$ LÉVY-BRUHL, Lucien. La morale et la science des moeurs. Paris: Felix Alcan, 1910.

${ }^{7}$ Não foi utilizado o termo "golpe" naquele momento.
} 
processo pelo qual nos tornamos "experts". O nosso pensar antropológico está relacionado com o lugar que a Antropologia ocupa na academia, na forma que ela é estabelecida nos departamentos e como ela construída por meio de teorias, conceitos, categorias, doxas, parâmetros, etc. Levamos a campo todo esse arsenal teórico-metodológico, juntamente com as nossas percepções de mundo, que vão, de alguma maneira, elaborar os dados etnográficos no encontro com o outro. Transformamos a realidade que nos cerca em categorias acadêmicas, definindo a nossa expertise e a nossa aceitação pelos pares. Nesse movimento entre realidade e academia, produzimos uma linguagem acadêmica que é reproduzida nos nossos livros, artigos, conferências, laudos, declarações públicas, etc. Acabamos nos afastando da realidade do trabalho de campo e nos aproximando do campo da Antropologia como disciplina científica (RAMOS, 1990). Assim, entra em campo uma cultura produzida por nós, antropólogos, pesquisadores, políticos. (ARANTES, 1984). A questão aqui é refletirmos sobre a cultura que estamos produzindo, indagando-nos sobre seus desdobramentos na política de preservação do patrimônio cultural. Como podemos perceber com o encontro entre baiana e antropólogo, essa cultura acadêmica não é neutra, sendo usada pelas detentoras como forma de distinção entre elas e entre os outros atores sociais, buscando-se mais uma forma de reconhecimento entre os aliados na política de patrimônio.

Da mesma maneira, seguindo os rastros dos desdobramentos da política de salvaguarda, que proporciona o encontro entre detentores e "experts" do patrimônio, podemos nos perguntar o que simbolizou para as baianas de acarajé tornarem-se patrimônio imaterial, depois da solicitação de registro pela Associação de Baianas de Acarajé e Mingau do Estado da Bahia, juntamente com o Centro de Estudos Afro-Orientais da Universidade Federal da Bahia e o Terreiro Ilê Axê Opô Afonjá, em 10 de dezembro de 2004. O ofício foi inscrito no Livro de Registro dos Saberes - volume primeiro, do Instituto do Patrimônio Histórico e Artístico Nacional (Iphan), instituído pelo Decreto 3551 de 4 de agosto de 2000 -, como patrimônio cultural brasileiro, a partir da decisão na $45^{\text {a }}$ Reunião do Conselho Consultivo do Patrimônio Cultural, realizada em $1^{\mathrm{o}}$ de dezembro de 2004 (IPHAN, 2004). Segundo Nina Bitar, o registro desse ofício desenhou-se "como uma demarcação de fronteiras entre as baianas e seus outros: os ambulantes e os evangélicos. Para elas, tornar-se patrimônio significou marcar uma alteridade, ora associando o acarajé às religiões afrobrasileiras, ora ao que entendem por tradição” (BITAR, 2011, p. 203). Assim, não podemos perder do horizonte as disputas presentes no campo das políticas de proteção dos patrimônios culturais.

\footnotetext{
Como antropólogos, não podemos desconsiderar que o diferencial de atribuição de valor, e a conseqüente apropriação diferenciada pelos diversos grupos, se dá em meio a conflitos sobre a construção das identidades, dos símbolos e do acesso a determinados bens culturais. Não podemos esquecer que a luta pelo poder de nomear o patrimônio é antes de tudo uma luta pelo poder de pôr em destaque uma "memória”, uma "história" (TAMASO, 2005, p. 23).
}

Entretanto, o registro dessa história é questionado na qualidade de sua utilidade prática na vida cotidiana das baianas, principalmente quando elas acionam o instrumento com o objetivo de vencer as dificuldades de legalização do ponto de trabalho. 
Percebe-se que, mesmo que o ofício das baianas de acarajé se tenha tornado patrimônio cultural brasileiro, essa ação não atingiu as expectativas das portadoras para resolverem as dificuldades enfrentadas na legalização do ponto de trabalho. Nesse sentido, como dito anteriormente, o Comitê vem se esforçando na tentativa de equacionar a questão das licenças, construindo uma parceria com a SEOP para agilizar os procedimentos burocráticos existentes. Nossa contribuição, por exemplo, sobre essas questões, insere-se nesta dinâmica de interpretar a recepção das práticas por parte dos detentores de bens patrimoniais, aprofundando os debates mais recentes dos patrimônios, para além do conhecimento prévio da manifestação cultural (TAMASO, 2005). A noção de patrimônio para as detentoras amplia-se com os encontros institucionais, uma vez que elas utilizam o entendimento sobre as categorias como "registro", "livro", "publicação", "reconhecimento", entre outras, na interlocução com outros atores sociais. Assim, é importante o antropólogo dedicar-se a analisar os empregos do patrimônio utilizados pelos representantes e detentores no espaço de discussão do Comitê.

Atento a essas características dinâmicas, o nosso maior desafio como pesquisador no campo do patrimônio cultural é darmos conta dos usos sociais do patrimônio, uma vez que as novas interações entre capital, estado e sociedade ultrapassam as questões de preservação que monopolizavam a bibliografia até então (CANCLINI, 1994). É importante que enfrentemos o desafio de compreender a produção de discriminações sofridas pelas baianas em seu dia a dia, relatadas nos trabalhos do Comitê, investigando os outros grupos religiosos que se apresentam intolerantes às crenças religiosas das baianas. Nesse seguimento, dialogando com os escritos de Latour (1997), devemos adotar uma noção de simetria, que se configura como sua "base moral", que nos permite refletir sobre o jogo interacional entre campos opostos, que organizam e constituem a atividade hermenêutica de busca de uma mediação analítica, exercício fundamental do trabalho de interpretação do antropólogo.

Neste trabalho, de maneira geral, as baianas demonstram serem reconhecidas por outros atores sociais. De um lado, o reconhecimento de uma antropóloga, uma vez que as baianas de acarajé tornam-se protagonistas da sua pesquisa. Por outro lado, o reconhecimento do poder público, que classifica o ofício das baianas de acarajé como patrimônio imaterial. Nesses dois casos, são produzidos documentos a partir do encontro e da troca entre culturas distintas, assim como no Comitê, onde temos baianas, pesquisadores(as), instituições, etc, que se reúnem para refletirem e desenvolverem a política de salvaguarda deste patrimônio. A partir desses encontros no Comitê, gostaria de problematizar o trabalho do antropólogo nesse ambiente interinstitucional, pois, como bem ressaltou Tamaso (2005), tratando do papel do "antropólogo inventariante", a questão não passa apenas pelo domínio do patrimônio em foco. "O nosso olhar antropológico deve estar atento às categorias que estão entrando em cena: 'inventário', 'referência cultural', 'patrimônio imaterial', 'registro' e interpretar criticamente os usos aos quais eles têm servido nos mais variados lugares" (TAMASO, p. 31, 2005). Dessa forma, precisamos investigar como as políticas de patrimônio processam as manifestações culturais e, concomitantemente, identificar como elas estão influenciando as práticas dos grupos detentores.

Nesse ambiente interinstitucional que caracteriza o Comitê, o antropólogo pode pensar essas reuniões como encontros antropológicos, onde acontecem 
trocas entre culturas distintas. Nessa relação dialógica, o antropólogo cumpre o papel de "mediador cultural", dialogando com o trabalho de Vovelle, que transita entre dois mundos - o acadêmico, o institucional e o popular. Pode-se compreendê-lo como um "guarda de trânsito", que se situa entre o universo dos dominantes e o dos dominados. "Ele adquire uma posição excepcional e privilegiada: ambígua também, na medida em que pode ser visto tanto no papel de cão de guarda das ideologias dominantes, como porta-voz das revoltas populares" (VOVELLE, 1987, p. 214). A questão que se coloca aqui é pensarmos na circulação da cultura (GINZBURG, 1993), a partir do encontro no Comitê, por exemplo, onde diversas instituições se reúnem, trazendo suas práticas institucionais, decorrentes das experiências dos seus membros participantes.

Essa troca nos apresenta a dimensão interativa do trabalho do antropólogo, uma vez que as categorias locais e acadêmicas são expostas no fazer etnográfico. Para exemplificar de forma mais clara, volto à experiência de trabalho de campo que tive anteriormente no projeto "Habitat Saudável" da Fiocruz. Nos nossos inúmeros encontros no interior da localidade "Curicica 1"8, uma das sete "comunidades", de acordo com a prefeitura, localizadas na área da antiga Colônia Juliano Moreira (CJM), os moradores e as moradoras questionavam os(as) pesquisadores(as) sobre o que nós achávamos do papel da prefeitura no contexto de implantação do Programa de Aceleração do Crescimento (PAC) na região de Jacarepaguá. De maneira geral, afirmávamos a importância de se cobrar e garantir os direitos sociais constitucionais, como moradia e saúde. Vale sublinhar, aqui, que essa é uma prática tradicional da antropologia brasileira, isto é, defender os direitos das populações dominadas deste país. "Talvez por sermos uma nação colonizada tenhamos desenvolvido esse pendor ativista" (RAMOS, 1990, p. 1), que busca de alguma forma uma justiça social. A partir dessa visão, eu mesmo inseri algumas vezes, em um contexto de diálogo com moradores sobre a história local, a categoria patrimônio, pois pensava essa categoria como uma chave para compreender a memória construída na relação com o poder público. Mas essa é outra questão, a questão que gostaria de apresentar aqui é a apropriação das categorias utilizadas pelos pesquisadores nos encontros do trabalho de campo. Assim, a ideia de patrimônio compartilhada por mim buscava pensar a memória social dos(as) moradores(as) da localidade "Curicica 1" como um patrimônio, a qual dialogava com a elaboração de José Reginaldo Gonçalves.

\begin{abstract}
(...) Simultaneamente em sua universalidade e em sua especificidade; reconhecidos ao mesmo tempo como necessários e contingentes; adquiridos (ou construídas e reproduzidas no tempo presente) e ao mesmo tempo herdados (recebidos dos antepassados, de divindades, etc.); simultaneamente materiais e imateriais; objetivos e subjetivos; reunindo corpo e alma; ligados ao passado, ao presente e ao futuro; próximos, ao mesmo tempo em que distantes; assumindo tanto formas sociais quanto formas textuais (por exemplo, nas etnografias e nos ensaios em que foram representados). O sentido fundamental dos "patrimônios" consiste talvez em sua natureza total e em sua função eminentemente mediadora (GONÇALVES, 2005, p. 30).
\end{abstract}

Nesses encontros dialógicos, a categoria patrimônio media a relação entre os atores sociais. Os moradores acionaram a memória social tecida em relação

\footnotetext{
${ }^{8}$ A palavra Curicica denomina um dos bairros da XVI RA (Região Administrativa) - Jacarepaguá, Anil, Curicica, Freguesia, Tanque, Gardênia Azul, Pechincha, Praça Seca, Taquara, Vila Valqueire.
} 
com o "Hospital de Curicica"9 no presente, dialogando com os saberes dos pesquisadores da Fiocruz, recriando novas possibilidades de atuação em um cenário de implantação do PAC. A história local ganhava uma nova roupagem de caráter patrimonial no enfrentamento das mudanças em curso. Esse exemplo serve para pensarmos na outra ideia que apresento neste trabalho a partir do encontro específico com a baiana de acarajé: a relação dialógica do ofício do antropólogo.

Paremos por aqui. Em síntese, busquei discutir, por um lado, os imbricamentos entre o patrimônio material e imaterial e os desafios no diálogo entre diversas concepções do patrimônio na implementação de políticas públicas de salvaguarda, na tentativa de ampliar o escopo dessas próprias categorias, investigando-as no seu caráter relacional e dinâmico. Por outro, investi na relação dialógica do ofício do antropólogo com o intuito de desvendar os usos e reinvenções de algumas categorias produzidas e proferidas na interação dos atores sociais no curso dos encontros institucionais $\mathrm{e}$ profissionais.

\section{Prospectiva}

Gostaria de finalizar este trabalho problematizando algumas questões presentes na relação entre antropólogo e baiana, uma vez que esse foi o foco desta investigação. Para tal finalidade, considero pertinente dialogar com os escritos de Míguez e Semán (2006), onde eles discutem a relação entre a cultura popular e cultura elitista. Nesse encontro intercultural, os autores avaliam os efeitos das diferenças de poder que existem entre essas duas culturas, ponderando as possibilidades de abolição dos recursos conceituais e ideológicos que consideram legítimos o ordenamento hierárquico entre as culturas. Este giro coloca a elaboração de uma cultura popular em uma encruzilhada decisiva. Se a relativização dos pressupostos etnocêntricos reabilita a alteridade cultural, é necessário reconhecer que esse mesmo movimento contém a propensão de ignorar as assimetrias de poder. Devemos investigar os conflitos de poder inscritos na constituição da cultura popular como uma cultura subalterna. É preciso encontrar e questionar as categorias alternativas que o dominante utiliza para se prevalecer como tal, já que, mesmo que as classes subalternas sejam dominadas, não quer dizer que elas devam ser descritas com as categorias dominantes. Nessa perspectiva, a meta que se apresenta para nós letrados, é conseguirmos articular nosso discurso analítico com as carências reais de pessoas concretas. Atuando com essa postura, podemos escolher a cultura popular como o nosso lado, investindo nossas forças nessa direção e ultrapassando os desvelamentos críticos sobre os mecanismos de dominação elaborados até então. Espera-se, pois, que este saber crítico produzido por nós seja capaz de transformar as condições concretas da vida dos espoliados da História. Entretanto, temos que ter o cuidado de não achar que somos protagonistas nesse processo, escamoteando o outro, o "subalterno", dado que

\footnotetext{
9 "Hospital de Curicica", como é chamado pelos(as) moradores(as) de "Curicica 1" atualmente o Hospital Municipal Raphael de Paula e Souza.
} 
os dominados não devem ser vistos apenas como objetos, isto é, temos que olhálos como sujeitos da sua própria história (MEYER, 1993).

Ao adotar essa perspectiva dialógica entre sujeitos, podemos voltar os nossos olhares ao próprio ofício das baianas de acarajé, vislumbrando novos conceitos que se assentem na maneira de estar e agir no mundo das baianas. Dialogando com a obra de Gonçalves (2007), podemos elaborar uma conversa entre a categoria "patrimônio", partindo das suas múltiplas representações, e as "formas de vida" e de "autoconsciência cultural" expressas nas manifestações culturais. As baianas vivenciam o espaço público, guiadas na relação com as religiões afro-brasileiras, trazendo outra possibilidade de se pensar a rua, associada a uma noção de casa de candomblé, conforme destacou Bitar (2011). Isso nos permite refletir sobre o ofício e espaço público em termos cosmológicos, ampliando-se a nossa noção de patrimônio. Nessa proposta, o patrimônio "faz a mediação sensível entre seres humanos e divindades, entre mortos e vivos, passado e presente, entre o céu e a terra, entre outras oposições" (GONÇALVES, 2007, p. 114). Na dinâmica dos encontros produzidos pelo patrimônio,

\begin{abstract}
na esfera da rua, o espaço público transfigura-se em uma espécie de casa, sendo domesticado a partir de atitudes cuidadosas em relação aos preceitos, às obrigações religiosas a serem seguidas, como o preparo dos sete pequenos bolinhos de acarajé para Iansã, uma vez que, como já vimos, é primordial o respeito e a aprovação de Iansã para a venda do acarajé. No caso de Ciça, a relação de dádiva com Ibêji ou Cosme e Damião, os meninos que agilizam as coisas, e com Exu, que protege a rua, é extremamente importante. Já para a baiana Nicinha, além de agradar Iansã e Ibêji, tem que fazer obrigações para Obaluaiê, o dono da barraca, pois é sua filha (BITAR, 2011, p. 219-220).
\end{abstract}

Nessas trocas entre baianas e divindades nas ruas da cidade, o espaço público é sacralizado. O ponto torna-se uma espécie de terreiro de rua, onde o visível e o invisível se entrelaçam, articulando-se o acarajé e as entidades. Nessa experiência de ser baiana, produz-se uma estética da resistência (ZAPATTA OLIVELLA, 2002), trazendo novas possibilidades de pensarmos a resiliência dos afrodescendentes e questionarmos o padrão branco, civilizado, europeu e católico, que excluía e negava a indigenidade e africanidade americana tanto no plano físico quanto no plano simbólico (ANNECCHIARICO, MARTÍN, 2012).

Nessa nova concepção, dialogando com Zapata Olivella (2002), é importante mover-se entre saberes, mitologias, histórias, realidades consideradas opostas, cosmogonias assimetricamente situadas, para pensarmos a pluralidade de comunidades existentes, que rompa com o racismo e a alienação social, política e econômica, as quais continuam existindo. Por fim, precisamos ter uma postura crítica que pense o patrimônio de maneira "descolonizante", na tentativa de ampliarmos nossa compreensão tanto da manifestação cultural em análise quanto dos seus usos sociais pelos atores envolvidos na política de patrimônio. 
ANNECCHIARICO, Milena; MARTÍN, Alicia (Org.). Afropolíticas em América del Sur y el Caribe. Buenos Aires, Puentes Del Sur Ediciones, 2012.

BITAR, Nina Pinheiro. Baianas de acarajé: comida e patrimônio no Rio de Janeiro. Rio de Janeiro: Aeroplano, 2011.

BRASIL. Ministério da Cultura. O Registro do Patrimônio Imaterial: Dossiê final das atividades da Comissão e do Grupo de Trabalho Patrimônio Imaterial. Brasília: Ministério da Cultura / Instituto do Patrimônio Histórico e Artístico Nacional, 2006.

CANCLINI, Nestor Garcia. O patrimônio cultural e a construção imaginária no nacional. In: HOLANDA, Heloísa Buarque (Org.). Revista do Patrimônio Histórico e Artístico Nacional. Brasília: Iphan, n. 23, p. 94-115, 1994.

DAMATTA, Roberto. O Ofício de Etnólogo ou como ter Anthropological Blues. In: NUNES, Edson de Oliveira (Org.). A aventura sociológica. Rio de Janeiro: Zahar Editores, 1978.

GINZBURG, Carlo. Prefácio à edição italiana. In: $O$ queijo e os vermes: o cotidiano e as idéias de um moleiro perseguido pela Inquisição. São Paulo: Companhia das Letras, 1993.

GOFFMAN, Erving. A representação do eu na vida cotidiana. Tradução Maria Célia Santos Raposo. Petrópolis: Vozes, 2008.

GONÇALVES, José Reginaldo Santos. Ressonância, materialidade e subjetividade: as culturas como patrimônios. Horizontes Antropológicos, Porto Alegre, ano 11, n. 23, p. 15-36, jan/jun 2005.

Janeiro, 2007.

Antropologia dos objetos: coleções, museus e patrimônios. Rio de

IPHAN. Patrimônio imaterial: fortalecendo o Sistema Nacional. Brasília: IPHAN, 2014.

Disponível

Ofício das Baianas de Acarajé. Livro de Registro dos saberes, 2004.

http://portal.iphan.gov.br/uploads/ckfinder/arquivos/BaianasdeAcarajeRegistr o.pdf. Acesso em: 16 set 2016.

JORNAL DO BRASIL. Cultura. Iphan inaugura mostra sobre prédio histórico da Avenida Rio Branco, 2012. Disponível em: http://www.jb.com.br/cultura/noticias/2012/o3/15/iphan-inaugura-mostrasobre-predio-historico-da-avenida-rio-branco/. Acesso em: 11 jun. 2016.

KAZ, Roberto. A diferença entre o acarajé e o sanduiche de Bauru. Revista de História da Biblioteca Nacional, n 13, out. 2006. 
LAPLANTINE, François. A descrição etnográfica. Tradução João Manuel Ribeiro Coelho e Sérgio Coelho. São Paulo: Terceira Margem, 2004.

LATOUR, Bruno. A etnografia das ciências. In: LATOUR, Bruno; WOOIGAR, Steve. A vida de laboratório: a produção dos fatos científicos. Rio de Janeiro: Relume Dumara, 1997.

MAUSS, Marcel. Ensaio sobre a dádiva: forma e razão da troca em sociedades Arcaicas. In: . Sociologia e Antropologia. São Paulo: EDUSP, 1974.

MEYER, Marlyse. Caminhos do imaginário no Brasil. São Paulo: EDUSP, 1993.

MÍGUEZ, Daniel; SEMÁN, Pablo (Orgs.). Entre santos, cumbias y piquetes: las culturas populares en la Argentina reciente. Buenos Aires: Editorial Biblos, 2006

OLIVEIRA, Roberto Cardoso de. O trabalho do antropólogo: olhar, ouvir, escrever. In: O trabalho do antropólogo. Brasília: Paralelo 15; São Paulo: UNESP, 2000.

O mal-estar da ética na antropologia prática. In: VÍCTORA, Ceres et al. (Orgs.). Antropologia e ética: o debate atual no Brasil. Niterói: EdUFF, 2004.

PIMENTA, Vítor Gonçalves. Corpo-arquivo: reflexões da memória encarnada em uma experiência etnográfica em Jacarepaguá. Dissertação (Mestrado) Universidade Federal Fluminense. Departamento de Antropologia, 2015.

RAMOS, Alcida Rita. O antropólogo: ator político, figura jurídica. Série Antropologia, Brasília, v. 92, p. 1-20, 1990.

TAMASO, Izabela. A expansão do patrimônio: novos olhares sobre velhos objetos, outros desafios... Sociedade e Cultura, V. 8, N. 2, JUL./DEZ. 2005, p. 13-36.

VELHO, Gilberto. Observando o familiar. In: NUNES, Edson de Oliveira (Org.). A aventura sociológica. Rio de Janeiro: Zahar Editores, 1978.

VOVELLE, Michel. Ideologias e mentalidades. São Paulo: Brasiliense, 1987.

ZAPATA OLIVELLA, Manuel. El árbol brujo de la libertad: África en Colombia. Buenaventura: Universidad del Pacífico, 2002.

\section{Recebido em 03/o6/2017. Aprovado em 12/09/2017.}

